TEMAS EMERGENTES

\title{
Protección del patrimonio cultural indígena en Chile
}

\author{
Protection of indigenous cultural heritage in Chile
}

Daniela Andrea Abarzúa Órdenes (iD)

Servicio Nacional del Patrimonio Cultural, Chile

\begin{abstract}
RESUMEN La promoción de los derechos culturales indígenas, concepto también asociado a la categoría "patrimonio cultural indígena», en cuanto discurso público instalado en las demandas sociopolíticas indígenas actuales, es todavía un tema emergente en Chile. Esto, a pesar de que hoy existe pleno consenso de la urgente necesidad de revitalizar y proteger los sistemas culturales originarios, pues constituyen el cimiento sobre el que descansan las expresiones culturales (lenguas, las tradiciones, oficios, noción del tiempo y el espacio entre tantas otras) que han mantenido activas y diferenciadas las identidades étnicas a través del tiempo. Este artículo indagará, desde la perspectiva del enfoque de los derechos humanos de los pueblos indígenas, el estado actual de los derechos culturales de estos pueblos en la legislación chilena e internacional vigente en el país. Asimismo, propondrá posibles alternativas de protección a estos derechos en el actual contexto legal vigente en Chile.
\end{abstract}

PALABRAS CLAVE Patrimonio cultural indígena, derechos humanos culturales indígenas, propiedad intelectual, conocimientos y expresiones culturales tradicionales indígenas.

ABSTRACT: The promotion of indigenous cultural rights - a notion entangled with the concept of "indigenous cultural heritage" - as a public discourse settled within current sociopolitical indigenous claims, remains as an underdeveloped topic in Chile. This, despite the full consensus that exists around the pressing need to revitalize and protect indigenous cultural systems (such as languages, traditions, crafts, time and space notions, among many others), which have allowed ethnic identities to remain active and distinguishable through time. By adopting an indigenous human rights perspective, the paper will explore the current situation of indigenous peoples' cultural rights within the Chilean and international applicable legislation. It will also suggest opportunities for the protection of these rights within the legal framework in force in Chile. 
KEYWORDS Indigenous cultural heritage, indigenous cultural human rights, intellectual property, indigenous traditional knowledge and cultural expressions.

\section{Introducción}

Existe hoy un consenso, más o menos general, de que hace unas cuatro décadas comenzó la eclosión de un fuerte activismo indígena, manifestado tanto a nivel local como en el ámbito internacional. Dicho fenómeno sociopolítico habría derivado en el establecimiento de una agenda con prolífica participación originaria en diversos foros y reuniones multilaterales. Esta presencia ha estado con frecuencia acompañada por una serie de intensas movilizaciones suscitadas en diversos territorios, en particular en América Latina. Este escenario sin duda ha sido uno de los ingredientes constitutivos para la creación del actual corpus internacional de derechos humanos de los pueblos indígenas.

Ejemplo evidente de esta situación fue la entrada en vigor internacional del Convenio 169 de la Organización Internacional del Trabajo (OIT), adoptado en Ginebra en 1989 luego de un largo proceso, en que participaron expertos y representantes indígenas y tribales. La naturaleza de este Convenio es de Tratado Internacional de Derechos Humanos Indígenas y Tribales y se ha instituido en la principal carta de navegación para las demandas indígenas contemporáneas, posibilitando junto con las Declaraciones Internacionales sobre Derechos de los Pueblos Indígenas (de Naciones Unidas en 2007 y la Organización de los Estados Americanos en 2016), un azaroso pero persistente fortalecimiento de los sistemas jurídicos locales en diversos países.

La implementación del corpus internacional de derechos humanos indígenas se ha traducido en muchos países - entre ellos, Chile - en la consolidación de la matriz de reivindicaciones históricas de los pueblos originarios dirigida hacia los Estados. Antecedente directo de ello es sin duda la incorporación forzada de estos pueblos a los respectivos Estados nacionales en América Latina y la posterior aparición a principios del siglo XX de lo que hoy llamamos «movimiento indígena». El derecho a la tierra y a la urgente ampliación de su cabida, afectada dramáticamente mediante esa incorporación, se ha transformado en la principal demanda contemporánea de esos pueblos, pues refiere a su propia existencia física actual y futura.

Un efecto directo de la institucionalización de esta demanda, a lo largo de más de un siglo, es que los discursos públicos del movimiento indígena aparezcan hegemonizados por el derecho a la tierra. Un resultado no deseado de esto es que los derechos culturales han pasado a constituirse en una reivindicación de segunda línea $o$ a lo menos subsumida en aquélla, a pesar de su relevancia y directa vinculación con el derecho a la vida de los pueblos, como expondremos aquí.

Ejemplo concreto de lo anterior fue el surgimiento en Chile de la Corporación Nacional de Desarrollo Indígena (Conadi), a través de la dictación en el año 1993 de 
la Ley Indígena 19.253, cuyo eje fundamental lo constituye el reconocimiento, protección y desarrollo de tierras indígenas, a través de un fondo para tierras y aguas indígenas, administrado por la propia Conadi.

La promoción de los derechos culturales indígenas, concepto también asociado a la categoría de patrimonio cultural indígena en cuanto discurso público instalado en las demandas sociopolíticas indígenas actuales, es todavía un tema emergente en Chile. Esto, a pesar de que hoy existe pleno consenso de la urgente necesidad de revitalizar y proteger los sistemas culturales originarios, pues constituyen el cimiento sobre el que descansan las expresiones culturales - como las lenguas, las tradiciones, oficios, noción del tiempo y el espacio, entre tantas otras- que han mantenido activas y diferenciadas las identidades étnicas en el tiempo.

A partir de lo enunciado, este artículo indagará desde la perspectiva del enfoque de los derechos humanos de los pueblos indígenas, y sobre todo desde la experiencia de terreno con actores sociales, gestores protagonistas de la creación y gestión cultural indígena, en el estado actual de los derechos culturales de estos pueblos en la legislación chilena e internacional vigente en Chile. Se explorarán en las conceptualizaciones, posibilidades y sobre todo las limitaciones que implican la conceptualización de patrimonio cultural indígena. Desde esta perspectiva, se examinará también un abanico de vulneraciones ligadas a este campo, como la apropiación, la invisibilización de las y los creadoras indígenas, la copia no autorizada del acervo cultural originario por parte de distintos actores, en apariencia muy diferentes, pero aquí contradictoriamente relacionados, como el comercio de productos con contenido étnico y la actividad de investigación académica.

Luego, se analizará el marco jurídico internacional vigente en Chile en materia de derechos culturales indígenas, para determinar las obligaciones contraídas por el Estado. A su vez, se analizará la principal normativa nacional vigente que regula algún aspecto de los elementos de conforman los patrimonios culturales indígenas.

Por último, a partir de lo expuesto, se propondrán posibles caminos de protección de esos patrimonios.

\section{¿Qué es el patrimonio cultural indígena?}

Tal como lo enunciamos, la conceptualización asociada a la denominación patrimonio cultural indígena es una categoría aún emergente dentro del mundo asociativo indígena. Dada esta realidad, cualquier análisis que pretenda adentrarse en este ámbito necesariamente debe comenzar por preguntarse sobre la viabilidad de tal conceptualización en el marco del abanico de problemáticas relacionadas que hoy afectan a estos pueblos. Desde esta consideración, es indudable que en términos generales esta denominación no satisface ni representa las necesidades indígenas actuales en Chile. 
Ocurre esto en gran medida porque el concepto aludido, tanto por su génesis como por sus contenidos asociados, no es capaz de abarcar de manera significativa el inconmensurable horizonte de contenidos y la multiplicidad de asuntos que contienen en su interior las distintas culturas indígenas. En efecto, no existe ni es posible que exista un solo patrimonio cultural indígena, definido y ordenado según categorizaciones construidas desde fuera. Lo que existe más bien son varios patrimonios culturales indígenas, cada uno asociado a su vez a las particulares configuraciones y particularidades de cada sistema cultural.

¿Cómo debiese establecerse entonces una definición que satisfaga las aspiraciones indígenas frente a este tema? Es indudable que las expresiones culturales son la base de sustentación sobre las que descansan las identidades étnicas, más aún en tiempos en que muchas se encuentran en crisis de reproducción. Por lo mismo, la protección de esos acervos constituye el fundamento no sólo de toda definición, sino que de la generación de mecanismos efectivos de protección definidos en diálogo con los y las protagonistas. Esta modificación de perspectiva nos lleva necesariamente a cambiar el paradigma de análisis. De esta forma, más que preocuparnos de cómo se definirían estos patrimonios culturales indígenas desde la mirada tradicional, sería necesario, como primer paso, acercarnos a los significados profundos de esos sistemas, tarea que, dada su dificultad, ameritaría un estudio específico - más allá de la mera descripción etnográfica- de estas culturas indígenas, tan desconocidas, ignoradas o tergiversadas.

Pensamos que una forma asequible de abordar aquella dimensión de los patrimonios culturales indígenas es indagar en las posibilidades que otorga el enfoque de derechos humanos, marco conceptual que permite concebirlos - en particular los referidos a los pueblos indígenas - desde una perspectiva integral. Dentro de esta definición, asumimos que los derechos son de carácter universal, indivisibles, interdependientes e interrelacionados, por lo que no opera ninguna jerarquía entre ellos. De esta forma, los derechos civiles y políticos no están por sobre los derechos sociales, económicos y culturales; al contrario, están unidos por un mismo cuerpo de principios, en los que no se puede afectar a un derecho sin afectar a otro, pues no existirían derechos humanos antagónicos ni jerarquizados. ${ }^{1}$

Este enfoque de los derechos humanos es tributario de la Conferencia Mundial de Derechos Humanos, celebrada en Viena en junio de 1993. Este evento se ha constituido en un hito para la historia de los derechos humanos, y tiene directa relación con distintos aspectos que tratamos aquí. En efecto, la aprobación de la Declaración y Programa de Acción emanados desde Viena fue un factor decisivo para la operativización de los derechos humanos que habían sido consagrados en diversos

1. Naciones Unidas, Declaración y Programa de Acción de Viena, aprobado el 25 de junio 1993, Conferencia Mundial de Derechos Humanos, numeral 5, p. 19. 
instrumentos internacionales. Además, la Declaración de Viena logró plasmar en su redacción el carácter indivisible e interdependiente de los derechos económicos, sociales, culturales, civiles y políticos, que se refuerzan mutuamente. De igual forma, en la Conferencia se denunciaron hechos de tortura, racismo, discriminación racial, ocupación y dominio extranjero, xenofobia, pobreza, hambre, intolerancia religiosa, terrorismo e incapacidad para mantener el imperio de la ley.

Resulta ilustrativo a nuestros fines ir al texto de la Declaración y Programa de Acción de Viena, numeral 5:

Todos los derechos humanos son universales, indivisibles e interdependientes y están relacionados entre sí. La comunidad internacional debe tratar a los derechos humanos en forma global y de manera justa y equitativa, en pie de igualdad y dándoles a todos el mismo peso. Debe tenerse en cuenta la importancia de las particularidades nacionales y regionales, así como de los diversos patrimonios históricos, culturales y religiosos, pero los Estados tienen el deber, sean cuales fueren sus sistemas políticos, económicos y culturales, de promover y proteger todos los derechos humanos y libertades fundamentales.

Asimismo, complementando el enfoque de los derechos humanos post Viena, en relación con la construcción de los patrimonios culturales indígenas, se debe destacar lo señalado en el informe de 1997 de la por entonces presidenta y relatora especial de la Subcomisión de Prevención de Discriminaciones y Protección de las Minorías para las Naciones Unidas, Erica-Irene Daes, cuando afirma:

21. [...] Los pueblos indígenas consideran que todos los productos de la mente y el corazón humanos están interrelacionados porque proceden de la misma fuente: el vínculo entre el pueblo y su tierra, y su afinidad con otras criaturas vivas con las que comparten la tierra y con el mundo de los espíritus. Como la propia tierra es en última instancia la fuente de conocimientos y creatividad, el arte y la ciencia de un determinado pueblo son manifestaciones de las mismas relaciones fundamentales y pueden considerarse como manifestaciones de todo el pueblo. [...]

23. [...] es más fácil y adecuado hablar de "patrimonio colectivo» de cada pueblo indígena, que hacer distinciones entre «propiedad cultural» $\mathrm{y}$ "propiedad intelectual» $[\ldots]$.

24. «Patrimonio» es todo lo que forma parte de la identidad característica de un pueblo, que puede compartir, si lo desea, con otros pueblos.

Esta expresión abarca todo lo que en la legislación internacional se considera como creación del pensamiento y de la destreza del ser humano como, por ejemplo, canciones, relatos, conocimientos científicos y obras de arte. Incluye también el patrimonio histórico y natural, como los restos humanos, las características naturales del paisaje y las especies vegetales y animales autóctonas con las que un pueblo ha estado tradicionalmente vinculado. 
Sin perjuicio de lo señalado por la relatora Daes en 1997, en las dos Declaraciones Internacionales sobre los Derechos de los Pueblos Indígenas surgidas a nivel global (Naciones Unidas en 2007) y a nivel continental (Organización de los Estados Americanos en 2016), a pesar de ser un avance substancial en materia de derechos humanos de los pueblos indígenas, se utilizaron los términos «propiedad del patrimonio cultural» $\mathrm{y}$ «propiedad del patrimonio intelectual». Ambas son categorías jurídicas derivadas de los sistemas normativos clásicos, que ponen el foco en la titularidad del derecho de propiedad occidental, entregando un monopolio económico al titular del derecho. Citamos textual:

Artículo 31: Los pueblos indígenas tienen derecho a mantener, controlar, proteger y desarrollar su patrimonio cultural, sus conocimientos tradicionales, sus expresiones culturales tradicionales y las manifestaciones de sus ciencias, tecnologías y culturas, comprendidos los recursos humanos y genéticos, las semillas, las medicinas, el conocimiento de las propiedades de la fauna y la flora, las tradiciones orales, las literaturas, los diseños, los deportes y juegos tradicionales y las artes visuales e interpretativas. También tienen derecho a mantener, controlar y desarrollar su propiedad intelectual de dicho patrimonio cultural, sus conocimientos tradicionales y sus expresiones culturales tradicionales (Declaración de las Naciones Unidas sobre los derechos de los pueblos indígenas, de 2007).

Artículo 28. Protección del Patrimonio Cultural y de la Propiedad Intelectual: 1. Los pueblos indígenas tienen derecho al pleno reconocimiento y respeto a la propiedad, dominio, posesión, control, desarrollo y protección de su patrimonio cultural material e inmaterial, y propiedad intelectual, incluyendo la naturaleza colectiva de los mismos, transmitidos a través de los milenios, de generación en generación (Declaración Americana sobre los derechos de los pueblos indígenas, de 2016).

Asumimos que esta mirada normativa institucional, más allá de su carácter promotor de derechos, puede considerarse al mismo tiempo como un riesgo para la protección efectiva de los patrimonios culturales indígenas. Esto sería así porque situaría en segundo plano la perspectiva del enfoque de derechos humanos, que permite promover la mirada de los propios actores indígenas, que desde esta óptica serían los llamados a dar contenido a la propiedad cultural e intelectual desde la óptica del derecho propio de los pueblos indígenas.

¿Cómo se articularía este derecho propio para el caso que nos ocupa? Una respuesta posible nos la proporcionan los propios actores indígenas.

Como se ha expresado ya, las y los diversos actores del manejo y gestión de las expresiones culturales tradicionales de los pueblos indígenas, tanto en el terreno de la enseñanza de las lenguas originarias, la creación artesanal tradicional, culturas gastronómicas, expresiones de música, danza, literatura y, en general, distintos gestores culturales en diversos territorios y pueblos, han manifestado a la autora, en diversas instancias, que no existiría una definición estática y única de lo que se denomina 
como patrimonios culturales indígenas. En todos los casos conocidos, se reitera que esta denominación no representa a este mundo, ya que no abarca ni comprende el complejo y diverso contenido de las culturas indígenas.

Otra consideración con frecuencia escuchada de parte de este sector es que, de aceptarse una definición de los patrimonios culturales indígenas, éste sería en cualquier caso un todo indivisible, ya que no debiera existir la división entre lo material y lo inmaterial, comprendiendo así tanto lo tradicional y lo contemporáneo. En este sentido, no hay una división clara de dónde comienza lo contemporáneo y termina lo tradicional, pues ambos espacios van de la mano y es muy difícil establecer un límite temporal a esta división artificial que involucra las propias trayectorias de vida de sus protagonistas. Tal consideración no debiese extrañarnos, ya que, para las distintas comunidades y sujetos indígenas, estos "patrimonios» están vigentes, al constituirse en la práctica activa y concreta de expresiones culturales desarrolladas en un espacio de ejercicio autónomo, al transmitirse de generación en generación. De ahí que la urgente revitalización y protección de este legado es la principal demanda que los pueblos indígenas le hacen al Estado chileno.

Cada pueblo indígena, en su unicidad, concibe de distinta manera sus propios "patrimonios», los cuales se relacionan directamente con sus sistemas culturales específicos y a su vez con sus territorios. Es de todo sentido que cualquier eventual instrumento legal que aspire a su protección permita dar cuenta de tal condición diversa, estableciendo en primer lugar la protección de sus «patrimonios propios» al menos en tres ámbitos fundamentales: recursos genéticos, conocimientos tradicionales y expresiones culturales tradicionales.

Sin perjuicio de lo señalado, la experiencia de terreno en varios territorios y con representantes de distintos pueblos, nos han posibilitado identificar un acercamiento general de estos patrimonios culturales indígenas, los cuales incluyen: ${ }^{2}$

- Territorio

- Concepto del tiempo y arte indígena

- Lengua, toponimia, cuentos, libros y relatos

- Materias primas y medicina tradicional

- Tecnología ancestral

- Conocimientos y expresiones tradicionales y contemporáneas

2. Obtenidos de los talleres participativos, realizados por la autora, «Derecho a la integridad cultural, el patrimonio cultural indígena y sus caminos de protección», entre 2016 y 2019, Subdirección Nacional de Pueblos Originarios, Servicio Nacional del Patrimonio Cultural, Ministerio de las Culturas, las Artes y el Patrimonio. 
- Alimentación, agua y semillas

- Artesanías, música, instrumentos, canciones y danza

- Cementerios, restos humanos de sus antepasados en museos nacionales y extranjeros

- Sitios sagrados o de significación cultural

- Madre tierra, humedales, naturaleza

- Comunidad, personas y celebraciones

- Símbolos, diseños y deportes ancestrales

- Cosmovisión, buen vivir, navegación y pesca ancestral

- Educación tradicional

- Historia, memoria, oficios tradicionales

Dada la complejidad y abundancia de cada elemento cultural mencionado, nos detendremos sólo en tres, considerados por los protagonistas indígenas como los substanciales. Destaca aquí el territorio como el eje articulador de las culturas indígenas, lo que quiere decir que los territorios tradicionales son el fundamento y sin ellos no podría haber culturas heredadas ni sustento sociocultural. De otro lado, el concepto del tiempo es el complemento perfecto que ordena los elementos culturales que contiene el territorio. Tiempo y espacio, entendidos según cada dinámica cultural específica, con sus códigos y claves de interpretación transmitidas de generación en generación, son la puerta de entrada a la comprensión de estas culturas. Al respecto, tan sólo considerar, a título de ejemplo genérico, que la noción del territorio y por tanto de su concepto espacio temporal es muy distinta entre la cultura rapa nui, de carácter polinésica, y las culturas andinas aymara o quechua, así como éstas son diferentes de la mapuche o a las culturas australes kawésqar o yagán.

El otro elemento central en este enfoque son las lenguas indígenas. En Chile en la actualidad están vigentes seis de ellas, además de otra como el ckunza, del pueblo atacameño o lickanantay, en proceso de rearticulación. De ahí la preocupación constante por la activación de procesos de revitalización autónoma de estas lenguas por parte de las propias organizaciones indígenas, este es el caso del mapuzugun, yagán, kawésqar, quechua, aymara, rapa nui y la lengua ckunza del pueblo atacameño o lickanantay. Los pueblos han manifestado que las lenguas maternas indígenas son el principal instrumento de transmisión y recreación de sus culturas y, a su vez, vehículo de influencia sobre la cultura criolla mestiza surgida a partir de la colonización europea, desde el siglo XVI hasta la actualidad.

Las lenguas indígenas le dan sentido a todo el entorno sociocultural de un colectivo humano. Les otorgan nombre, sentido y pertenencia a los paisajes culturales; son 
mecanismos de intercambio y diálogo intercultural al posibilitar su aprendizaje por los sujetos propios y ajenos, entre otras muchas posibilidades.

Estos son algunos de los elementos que componen los patrimonios culturales indígenas, los que se debe tener presente al momento de pensar en la protección de estos patrimonios.

\section{Las vulneraciones a los patrimonios culturales indígenas en Chile ${ }^{3}$}

Lamentablemente, en el espacio transversal de los actores de los patrimonios culturales indígenas, existe hoy un elemento en común que unifica toda evaluación acerca del estado actual de sus conocimientos y expresiones culturales. La historia de la incorporación de estos pueblos al Estado-nación fue, en todos los casos, sin excepción, traumática y plagada de episodios de violencia real y simbólica que entretejen la memoria colectiva contemporánea, con marcas que alcanzan hasta hoy. Las primeras generaciones indígenas alfabetizadas en los albores del siglo XX tuvieron que experimentar en carne propia la imposición de una lengua ajena, varios de sus rituales erradicados, sus símbolos tergiversados y su historia proscrita. Pese a que estas expresiones lograron sobrevivir, muchas veces encubiertas, hoy parte importante de estos «patrimonios» se les considera amenazados de forma sistemática y recurrente por múltiples factores externos.

Por su parte, el listado de estas vulneraciones abarca un amplio espectro de campos y actores sociales, públicos y privados. Algunas de estas vulneraciones son deliberadas, otras inconscientes y provocadas incluso con ánimo de «ayudar» a comunidades y gestores indígenas. Caben aquí tanto las industrias extractivistas que se disputan los recursos naturales presentes en los territorios indígenas; los entes públicos que intervienen los territorios con mensajes y estrategias contrapuestas entre diferentes órganos públicos al intervenir el mismo territorio; el etnoturismo y su apropiación del discurso indígena; la investigación etnográfica; los museos en tanto depositarios de la memoria intelectual y material de los pueblos; el relato comunicacional con aspiraciones etnográficas; la investigación académica autorreferente; la política con la utilización de las demandas originarias, entre tantas otras.

Hacer una lista acabada de ejemplos seria lato a los fines de este trabajo. Bástenos, sin embargo, con ejemplos acotados pero elocuentes que ilustran esta situación. Es habitual el caso de las artesanas indígenas, quienes muchas veces tienen serias dificultades de acceso a las materias primas esenciales para el desarrollo de su oficio, ya sea porque, dada la situación de degradación socioambiental de sus propios espacios, éstos ya no proporcionan estos insumos, por lo que deben recurrir a terrenos priva-

3. Fuente propia, relatos de denuncia de personas pertenecientes a pueblos originarios, trabajo territorial. 
dos o pertenecientes a parques nacionales, donde tienen dificultades o prohibición de acceso. Otros aspectos generalmente mencionados son la homologación de técnicas, materialidades y diseños indígenas promovida por presión de la demanda comercial; también el uso no autorizado e ilegítimo de diseños propios por parte de terceros, incluida la apropiación comercial y el uso indebido; la representación falsa o errónea, además de la utilización despectiva u ofensiva de la artesanía tradicional indígena, entre tantas otras.

\section{Marco jurídico internacional vigente en Chile}

Para llevar a cabo este análisis es necesario tener presente que, hasta la Segunda Guerra Mundial, el derecho internacional público —salvo situaciones muy específicas, como el combate a la esclavitud y establecimiento de derechos sociales mínimos abordados con la fundación de la OIT en 1919- no se preocupó por los derechos humanos, pues se consideraban asuntos de la jurisdicción interna de los Estados.

Consecuencia directa de la Segunda Guerra Mundial, en la que se atentó contra los derechos de la persona humana por el sólo hecho de pertenecer a un grupo humano o profesar una ideología, es que se motivó a la comunidad internacional, al término de la guerra a:

Reafirmar la fe en los derechos fundamentales del hombre, en la dignidad y el valor de la persona humana, en la igualdad de los derechos de hombres y mujeres (preámbulo de la Carta de Naciones Unidas, 1945).

En este contexto, y desde la perspectiva del derecho internacional, los derechos humanos pueden definirse como:

Atributos inherentes a toda persona humana que, al ser reconocidos e incorporados a un instrumento internacional vinculante, establecen para los correspondientes Estados la obligación de respetarlos y garantizar su ejercicio y permiten a las personas destinatarias de estos derechos invocarlos frente al Estado en que se hallen (Vargas, 2017: 490).

A fines del siglo XX, internacionalmente se ha logrado el reconocimiento de derechos humanos específicos de los pueblos indígenas. Éste ha sido el resultado de un proceso de movilizaciones organizadas por parte de los pueblos indígenas que se inician mucho antes de la creación de los sistemas supranacionales de protección a los derechos humanos. Sin embargo, no fue sino hasta la creación de estos sistemas que los derechos humanos indígenas lograron su reconocimiento y protección.

Es importante recordar un tema ya abordado en este artículo, a saber, que los derechos humanos son universales, indivisibles e interdependientes entre sí, reconocidos con este carácter en varios instrumentos internacionales. Tal situación fue 
reiterada en la Declaración de Jefes de Estado y de Gobierno de la Cumbre Mundial de 2005:

Reiteramos que todos los derechos humanos son universales e indivisibles, están relacionados entre sí, son interdependientes y se refuerzan mutuamente, y que deben tratarse de manera justa y equitativa y en pie de igualdad y con la misma atención. ${ }^{4}$

Se aprecia, entonces, que se ha reconocido a los pueblos indígenas su derecho a preservar su identidad, integridad y patrimonios culturales a través de instrumentos de derechos humanos sobre los derechos culturales de aplicación general, además de otros específicos para los pueblos indígenas.

De esta forma, este nuevo corpus de derechos indígenas rompe con la tradición tutelar anterior, por la cual los Estados consideraban que los territorios y los pueblos mismos estaban bajo su dominio y tutela y, por ende, bajo su sólo arbitrio. De ahí las políticas de asimilación, integración forzada e incluso desaparición física y cultural que caracterizaron eras pasadas. El fundamento de este corpus es el derecho que tienen los pueblos a vivir de determinada manera. Del derecho de existencia de los pueblos indígenas es que se desprende su derecho a la libre determinación. (Yrigoyen, 2011: 1).

Resulta evidente que los derechos humanos indígenas están en permanente gestación y al mismo tiempo reconfiguración. No existe, entonces, una carta cerrada y definitiva, ya que el contenido sustantivo de sus derechos no son el resultado de una humanidad única y estática, sino que por el contrario, pueden tener un carácter local y particular, apoyados en concepciones culturales diversas (Etxeberria, 2006: 43-83).

Así vistas las cosas, hoy se identifica claramente una tensión entre la teoría clásica de los derechos humanos y las reivindicaciones de los derechos de los pueblos indígenas, respecto sobre todo de su identidad colectiva y sus diversos patrimonios históricos, culturales y religiosos. Todos estos elementos vienen sin duda a matizar el carácter «universal» de los derechos humanos planteados en la Conferencia de Viena.

Existe un desafío mayor para el sistema universal de los derechos humanos, que es lograr una nueva relación de equilibrio dinámico entre el principio de igualdad y el principio de reconocimiento de la diferencia y avanzar hacia una concepción intercultural de los derechos humanos, logrando de esta forma la creación de condiciones que permitan a los derechos humanos ponerse al servicio de una política progresista y emancipadora (De Sousa Santos, 2016: 65-98). Estos temas son complejos y están en desarrollo, por lo que requieren de un estudio especial.

Esbozadas estas zonas de tensión, corresponde ahora analizar algunos de los principales instrumentos internacionales que consagran derechos culturales indígenas en el Sistema Internacional de Derechos Humanos.

4. Asamblea General de las Naciones Unidas, Resolución 6o/1, párr. 121. 


\section{Declaración Universal de Derechos Humanos}

Proclamada el 10 de diciembre de 1948 por la Asamblea General de Naciones Unidas en París, mediante la Resolución 217, como un ideal común para todos los pueblos y naciones, establece en su artículo 27:

1) Toda persona tiene derecho a tomar parte libremente en la vida cultural de la comunidad, a gozar de las artes y a participar en el progreso científico y en los beneficios que de él resulten.

2) Toda persona tiene derecho a la protección de los intereses morales y materiales que le corresponden por razón de las producciones científicas, literarias o artísticas de que sea autora.

\section{Pacto Internacional de Derechos Civiles y Políticos (PIDCP)}

Adoptado por la Asamblea General de las Naciones Unidas el 16 de diciembre de 1966 y suscrito por Chile en esa misma fecha, finalmente ratificado y promulgado por medio del Decreto Supremo 778, del 29 de abril de 1989.

En este instrumento se reconocen, en el artículo 1, el derecho a la libre determinación de los pueblos y el derecho de los pueblos sobre sus recursos naturales:

1) Todos los pueblos tienen el derecho a la libre determinación. En virtud de este derecho establecen libremente su condición política y proveen asimismo a su desarrollo económico, social y cultural.

2) Para el logro de sus fines, todos los pueblos pueden disponer libremente de sus riquezas y recursos naturales, sin perjuicio de las obligaciones que deriven de la cooperación económica internacional basada en el principio de beneficio recíproco, así como del derecho internacional. En ningún caso podría privarse a un pueblo de sus propios medios de subsistencia.

A su vez, el PIDCP reconoce el derecho a la cultura en el artículo 27:

En los Estados en que existan minorías étnicas, religiosas o lingüísticas, no se negará a las personas que pertenezcan a dichas minorías el derecho que les corresponde, en común con los demás miembros de su grupo, a tener su propia vida cultural, a profesar y practicar su propia religión y a emplear su propio idioma.

\section{Pacto Internacional de Derechos Económicos, Sociales y Culturales (PIDESC)}

Adoptado por la Asamblea General de las Naciones Unidas el 16 de diciembre de 1966 y suscrito por Chile en esa misma fecha, finalmente promulgado por medio del Decreto Supremo 326, del 27 de mayo de 1989. 
En este instrumento se reconocen una serie de derechos culturales interrelacionados entre sí, en su artículo 15:

1) Los Estados parte en el presente Pacto reconocen el derecho de toda persona a:

a) Participar en la vida cultural.

b) Gozar de los beneficios del progreso científico y de sus aplicaciones.

c) Beneficiarse de la protección de los intereses morales y materiales que les correspondan por razón de las producciones científicas, literarias o artísticas de que sea autora.

En ambos pactos (PIDCP y PIDESC) se reconoce que el derecho de los pueblos sobre sus recursos naturales está relacionado con el ejercicio del derecho de libre determinación de los pueblos, lo que permitirá la implementación de sus propios modelos de desarrollo. Así se encuentra establecido en el respectivo inciso segundo del artículo 1.

Cabe destacar que el comité a cargo de la supervisión del PIDESC en su Observación 21 de 2009, sobre el derecho de toda persona a participar de la vida cultural, contiene un acápite especial referido a los pueblos indígenas. Se relevan allí las obligaciones que los Estados parte tienen de reconocer, respetar y garantizar el derecho a participar en la vida cultural de los pueblos indígenas, destacando la dimensión colectiva de valores de la vida cultural indispensable para su existencia, bienestar y desarrollo integral.

\section{Convención Americana sobre los Derechos Humanos}

La conferencia especializada de la Organización de los Estados Americanos (OEA), sobre la base de un proyecto presentado por la Comisión Interamericana de Derechos Humanos, adoptó la Convención el 22 de noviembre de 1969, promulgada en Chile a través del Decreto 873 del Ministerio de Relaciones Exteriores en agosto de 1990.

Este instrumento es fundamental en el Sistema Interamericano de Derechos Humanos, pues la jurisprudencia de la Corte IDH, a través de la interpretación evolutiva o dinámica, ha dotado de nuevos contenidos a derechos expresamente reconocidos en la Convención, interpretando las disposiciones a la luz de las nuevas realidades contemporáneas. Así por ejemplo, encontró que el artículo 21 de la Convención, referido al tradicional derecho de propiedad, contenía en su esencia el reconocimiento al derecho de propiedad comunal y al territorio de los pueblos indígenas y, por ende, a consulta previa, libre e informada.

La sentencia de la Corte IDH en el caso de Saramaka con Surinam (2007) estableció que en megaproyectos que puedan afectar el modo de vida de los pueblos - como pasa en los supuestos traslados por la construcción de represas o ciertas actividades 
extractivas - no basta la consulta previa, sino que se requiere de un consentimiento previo, libre e informado.

\section{Convención sobre la Protección del Patrimonio Mundial, Cultural y Natural}

Adoptada en Conferencia General de Unesco en noviembre de 1972, promulgada en Chile en el Decreto 259 del Ministerio de Relaciones Exteriores en 1980. Regula el patrimonio material, distinguiendo entre patrimonio cultural (monumentos, conjuntos y lugares) y el patrimonio natural (monumentos naturales, formaciones geológicas y fisiológicas, y lugares o zonas naturales).

Esta Convención creó la «Lista de patrimonio mundial», que es una nómina de bienes patrimoniales culturales y naturales, con valor para toda la humanidad y no sólo para el país o comunidad de que se trate. Por ejemplo, Chile tiene inscrita en esa lista el Parque Nacional Rapa Nui desde el año 1995.

\section{Convención sobre los Derechos del Niño}

Adoptada por la Asamblea General de las Naciones Unidas en noviembre de 1989, promulgada en Decreto 830 del Ministerio de Relaciones Exteriores en 1990. Destaca lo establecido en su artículo 30 :

En los Estados en que existan minorías étnicas, religiosas o lingüísticas o personas de origen indígena, no se negará a un niño que pertenezca a tales minorías o que sea indígena el derecho que le corresponde, en común con los demás miembros de su grupo, a tener su propia vida cultural, a profesar y practicar su propia religión, o a emplear su propio idioma.

\section{Convención sobre la Diversidad Biológica}

Adoptada por la Asamblea General de las Naciones Unidas en noviembre de 1992, promulgada en Decreto 1.963 del Ministerio de Relaciones Exteriores en 1994. Se destaca lo establecido en su artículo 8 , letra j):

Con arreglo a su legislación nacional, respetará, preservará y mantendrá los conocimientos, las innovaciones y las prácticas de las comunidades indígenas y locales que entrañen estilos tradicionales de vida pertinentes para la conservación y utilización sostenible de la diversidad biológica y promoverá su aplicación más amplia, con la aprobación y participación de quienes posean estos conocimientos, innovaciones y prácticas, y fomentará que los beneficios derivados de la utilización de esos conocimientos, innovaciones y prácticas se compartan equitativamente. 


\section{Convención para la Salvaguardia del Patrimonio Cultural Inmaterial}

Adoptada por la Conferencia General de Unesco en octubre de 2003, promulgada por Decreto 11 del Ministerio de Relaciones Exteriores en 2009. Desataca lo establecido en su artículo 2:

1. Se entiende por «patrimonio cultural inmaterial» los usos, representaciones, expresiones, conocimientos y técnicas - junto con los instrumentos, objetos, artefactos y espacios culturales que les son inherentes- que las comunidades, los grupos y en algunos casos los individuos reconozcan como parte integrante de su patrimonio cultural. [...]

2. El «patrimonio cultural inmaterial» [...] se manifiesta en particular en los ámbitos siguientes:

a) tradiciones y expresiones orales, incluido el idioma [...].

b) artes del espectáculo;

c) usos sociales, rituales y actos festivos;

d) conocimientos y usos relacionados con la naturaleza y el universo;

e) técnicas artesanales tradicionales.

3. Se entiende por «salvaguardia» las medidas encaminadas a garantizar la viabilidad del patrimonio cultural inmaterial, comprendidas la identificación, documentación, investigación, preservación, protección, promoción, valorización, transmisión [...] y revitalización de este patrimonio en sus distintos aspectos.

\section{Convención sobre la Protección y Promoción de la Diversidad de las Expresiones Culturales}

Adoptada por la Conferencia General de Unesco en octubre de 2005, promulgada por Decreto 82 del Ministerio de Relaciones Exteriores en 2007. Establece en su artículo 4:

1. La «diversidad cultural» se refiere a la multiplicidad de formas en que se expresan las culturas de los grupos y sociedades [...] la diversidad cultural se manifiesta no sólo en las diversas formas en que se expresa, enriquece y transmite el patrimonio cultural de la humanidad mediante la variedad de expresiones culturales, sino también a través de distintos modos de creación artística, producción, difusión, distribución y disfrute de las expresiones culturales.

\section{Convenio 169 de la OIT sobre los Pueblos Indígenas y Tribales en Países Independientes}

Adoptada por la Conferencia General de la Organización Internacional del Trabajo (OIT) en junio de 1989, fue promulgada por el Decreto 236 del Ministerio de Relaciones Exteriores el 14 de octubre de 2008, y entró en vigor el 15 de septiembre de 2009. 
El Convenio 169 consagra derechos específicos a los pueblos indígenas y tribales, es decir, es un tratado internacional de derechos humanos que se encuentra dirigido íntegra y exclusivamente a dichos pueblos. Establece que estos pueblos indígenas y tribales son sujetos de derechos colectivos, por lo que reconoce derechos específicos para estos pueblos en su dimensión colectiva e individual. Destaca lo establecido en el artículo 2:

1. Los gobiernos deberán asumir la responsabilidad de desarrollar, con la participación de los pueblos interesados, una acción coordinada y sistemática con miras a proteger los derechos de esos pueblos y garantizar el respeto de su integridad.

2. Esta acción deberá incluir medidas: [...] b) que promuevan la plena efectividad de los derechos sociales, económicos y culturales de esos pueblos, respetando su identidad social y cultural, sus costumbres y tradiciones, y sus instituciones.

A su vez, el artículo 4 establece:

1. Deberán adoptarse las medidas especiales que se precisen para salvaguardar las personas, instituciones, los bienes, el trabajo, las culturas y el medio ambiente de los pueblos interesados.

2. Tales medidas especiales no deberán ser contrarias a los deseos expresados libremente por los pueblos interesados.

Los Estados que han suscrito el Convenio no pueden tomar medidas que vayan en contra de los intereses de los pueblos indígenas y tribales que en su libre determinación expresen. Como se ha señalado, históricamente los Estados han adoptado medidas para supuestamente favorecer el progreso cultural de los pueblos, las que se han traducido en asimilación forzosa e incluso genocidio. Ejemplos son los numerosos casos en toda América, tanto en el hemisferio norte como en el sur, de traslados forzosos de niños y niñas indígenas de sus territorios tradicionales, a excusa de «educarlos» con supuestos fines de «integrarlos a la civilización» en escuelas lejos de sus familias.

El Convenio 169, entonces, supera el carácter asimilacionista e integracionista de instrumentos anteriores - como el Convenio 107 de la OIT, de 1957-, al elevar el estándar. Reconoce las aspiraciones de los pueblos indígenas a controlar sus instituciones y formas de vida, y su modelo de desarrollo, manteniendo y fortaleciendo sus identidades, lenguas, y religiones, dentro de los Estados en que viven.

Se debe considerar lo establecido en el artículo 5, sobre derecho a la integridad cultural:

a) Deberán reconocerse y protegerse los valores y prácticas sociales, culturales, religiosos y espirituales propios de dichos pueblos y deberá tomarse debidamente en consideración la índole de los problemas que se le plantean tanto colectivamente como individualmente; 
b) deberá respetarse la integridad de los valores, prácticas e instituciones de esos pueblos [el subrayado es nuestro];

c) deberán adoptarse, con la participación y cooperación de los pueblos interesados, medidas encaminadas a allanar las dificultades que experimenten dichos pueblos al afrontar nuevas condiciones de vida y trabajo.

El derecho a la integridad cultural implica la protección de la identidad social, cultural, costumbres, tradiciones, instituciones propias y formas de vida de los pueblos indígenas.

Por su parte, el derecho de los pueblos indígenas a desarrollar su vida cultural y sistemas institucionales propios tiene reconocimiento en el artículo 8:

1. Al aplicar la legislación nacional a los pueblos interesado deberán tomarse en consideración sus costumbres o su derecho consuetudinario.

2. Dichos pueblos deberán tener el derecho de conservar sus costumbres e instituciones propias, siempre que éstas no sean incompatibles con los derechos fundamentales definidos por el sistema jurídico nacional ni con los derechos humanos internacionalmente reconocidos. Siempre que sea necesario, deberán establecerse procedimientos para solucionar los conflictos que puedan surgir de la aplicación de este principio.

$\mathrm{Al}$ establecerse en el Convenio 169 que los pueblos indígenas tienen derecho a asumir el control de sus propias instituciones y formas de vida, es que precisamente se explica el origen y fundamento de los derechos de participación, consulta y consentimiento previo, libre e informado. Estos derechos posibilitan a los pueblos a intervenir en los procesos de toma de decisión de políticas estatales que los afecten, asegurando de esta forma políticas de gobernanza de acuerdo con sus propios modelos de desarrollo.

Por último, el Convenio establece en sus partes 2, 4, 5 y 6 otros derechos económicos, sociales y culturales, como la contratación y condiciones de empleo, formación profesional, artesanía e industrias rurales, seguridad social, salud, educación y medios de comunicación.

\section{Declaración de las Naciones Unidas sobre Derechos de los Pueblos Indígenas (DNUDPI)}

Aprobada por la Asamblea General de Naciones Unidas el 13 de septiembre de 2007 con el voto favorable de 144 Estados, incluido Chile. Este es otro instrumento internacional sobre derechos humanos específicos de pueblos indígenas.

Entre los derechos que se destacan está el derecho a la libre determinación de los pueblos indígenas (artículo 3). La DNUDI reconoce el derecho de los pueblos indígenas a garantizar su integridad cultural mediante su derecho a la libre determinación. 
En virtud de este derecho, los pueblos pueden determinar libremente su condición política y perseguir su desarrollo económico, social y cultural.

Del mismo modo, se les reconoce en este instrumento su derecho a practicar y revitalizar sus tradiciones y costumbres culturales, la reparación por mecanismos eficaces y la restitución de bienes culturales, intelectuales, religiosos y espirituales que hayan sido privados sin consentimiento libre (artículo 11).

Se reconoce el derecho de utilizar y controlar sus objetos de culto y a obtener la repatriación de sus restos humanos y de culto (artículo 12). También tienen derecho a revitalizar, utilizar, fomentar y transmitir a las generaciones futuras sus historias, idiomas, tradicionales orales, filosofías, sistema de escritura y literaturas (artículo 13). Otro derecho que se destaca es el derecho a establecer y controlar sus sistemas e instituciones docentes que impartan educación en sus propios idiomas (artículo 14).

Por último, la DNUDPI, en su artículo 31, establece el derecho de los pueblos indígenas a mantener, controlar y desarrollar la propiedad intelectual de su patrimonio cultural, sus conocimientos tradicionales y sus expresiones culturales tradicionales.

\section{Declaración Americana sobre los Derechos de los Pueblos Indígenas (DADPI)}

Este es el último instrumento internacional sobre derechos humanos específicos de pueblos indígenas. Aprobada por la Asamblea General de la OEA el 15 de junio de 2016 después de diecisiete años de negociaciones, lo que significó un paso histórico al reconocimiento, promoción y protección de los derechos de más de 50 millones de personas indígenas en América.

Reconoce, al igual que la DNUDPI, el derecho a la libre determinación de los pueblos de su condición política y su desarrollo económico, social y cultural. De tal forma, esta declaración contiene varios derechos que se relacionan con el reconocimiento, promoción y protección de los patrimonios culturales indígenas, destacándose el derecho a la identidad e integridad cultural y a su patrimonio cultural (artículo 13). Por su parte, el artículo 14 reconoce los sistemas de conocimiento, lenguaje y comunicación. Asimismo, el derecho a la educación se reconoce en el artículo 15. Por último, la DADPI reconoce en su artículo 28 el derecho a la protección del patrimonio cultural y de la propiedad intelectual de los pueblos indígenas.

Del análisis a los principales instrumentos internacionales que reconocen y garantizan derechos culturales en general e indígenas en particular, en directa relación con los patrimonios culturales indígenas, podemos distinguir entre aquellos instrumentos internacionales cuya naturaleza jurídica es de tratado internacional. Éstos siempre tienen un efecto obligacional respecto del Estado en el ámbito internacional y la correlativa obligación interna de concretar el cumplimiento de estos compromisos internacionales en el propio derecho interno. Muchas veces no queda claro quién debería cumplir dicha obligación internamente, lo que provoca las denominadas bre- 
chas de implementación de los tratados internacionales respecto del derecho interno, en las que no se adecúa la normativa nacional interna a las obligaciones internacionales. Tal situación se ve reflejada en el análisis de la legislación interna en materia de derechos culturales respecto de los patrimonios culturales de pueblos indígenas.

Sin perjuicio de lo señalado, existen al menos tres instrumentos de los analizados que tienen el estándar más alto en materia de reconocimiento de derechos culturales indígenas: el Convenio 169 de la OIT, la Declaración de Derechos de Pueblos Indígenas de Naciones Unidas y la Declaración Americana de Derechos de Pueblos Indígenas del año 2016. Esta tríada de instrumentos internacionales, a pesar de tener una naturaleza jurídica diversa - esto es, tratado internacional de derechos humanos indígenas y soft law- ${ }^{5}$ constituyen el estándar más alto para el reconocimiento, ejercicio y protección de los derechos culturales indígenas respecto de sus propios patrimonios culturales.

\section{Normativa nacional vigente en Chile respecto de los patrimonios culturales indígenas}

A continuación, se analizará la principal normativa nacional, que regula determinados aspectos de los elementos que pueden constituir los patrimonios culturales indígenas, con el objeto de aclarar si otorgan o no algún tipo de protección o reconocimiento.

Ley 19.253 (1993), sobre Protección, Fomento, y Desarrollo de los Indígenas, y crea la Corporación Nacional de Desarrollo Indígena

Aunque en su momento esta ley fue considerada un avance histórico en materia de reconocimiento de los diversos pueblos indígenas que habitan el país, a poco andar -debido al momento histórico global en que fue promulgada y la movilización indígena que sobrevino en los años posteriores a 1993 - se demostró que parte importante de su articulado estaba desfasado respecto de la realidad contingente.

En primer lugar, esta ley, promulgada cuatro años después del Convenio 169, reconoce a las principales «etnias indígenas de Chile» y les otorga algunos derechos específicos. En este punto se produce una primera brecha con el Convenio 169 de la OIT, ya que éste reconoce claramente a los pueblos indígenas como sujetos de derechos colectivos.

Así también, el artículo 7 reconoce el derecho de los indígenas a mantener y desarrollar sus propias manifestaciones culturales, en todo lo que no se oponga a la

5. Soft law puede tener una función normativa, esto es, puede influenciar la conducta de los Estados a través de su aplicación directa por los operadores jurídicos e incluso se puede llegar a reconocer como derecho consuetudinario o costumbre internacional. 
moral, a las buenas costumbres y al orden público, estableciendo la responsabilidad de promover a las culturas indígenas al propio Estado.

Cierto es que el artículo 19 reconoce un derecho específico y colectivo sobre sitios de significación cultural, para poder llevar a cabo actividades culturales y solicitar la propiedad de estos espacios, si son fiscales, por parte de las comunidades indígenas, y el derecho a reclamación judicial en el caso de negarles estos derechos.

Esta ley establece el reconocimiento, respeto y protección de las culturas e idiomas indígenas, a través de varios mecanismos principalmente relacionados con el Ministerio de Educación (artículo 28). Además, contempla el desarrollo de un sistema intercultural bilingüe en áreas de alta densidad indígena en su artículo 32.

Otro punto para destacar es la creación de un departamento llamado «Archivo General de Asuntos Indígenas», dependiente del Archivo Nacional del Servicio Nacional del Patrimonio Cultural (SNPC), con sede en Temuco, que reunirá y conservará todos los documentos oficiales que se vayan generando sobre materias indígenas. El SNPC podrá organizar secciones de este archivo en otras regiones del país referidas a agrupaciones y culturas indígenas particulares (artículo 30, modificado por la Ley 21.045).

\section{Ley 17.288 (1970), de Monumentos Nacionales}

Es la norma nacional que contiene los principales reconocimientos al patrimonio cultural a secas. Establece categorías de protección: monumentos históricos, públicos, arqueológicos y zonas típicas, los que quedan bajo la tutela del Consejo de Monumentos Nacionales (CMN), declarados por decreto, salvo en el caso de los monumentos públicos y arqueológicos, que lo son por el sólo ministerio de la ley. Otra categoría que crea la ley es la de santuarios de la naturaleza, que pertenecería al patrimonio natural, y así se reconoció al instaurarse la nueva institucionalidad ambiental, traspasándose su tutela al Ministerio del Medio Ambiente (Chuvretovic, 2016: 153-164).

De acuerdo con el marco jurídico internacional analizado, existe una primera tensión entre los derechos reconocidos a los pueblos indígenas respecto de su patrimonio cultural y los reconocidos al Estado en la Ley de Monumentos Nacionales, artículo 1:

Son monumentos nacionales y quedan bajo la tuición y protección del Estado los lugares, ruinas, construcciones u objetos de carácter histórico artístico; los enterratorios o cementerios u otros restos de los aborígenes, las piezas u objetos antropoarqueológicos, paleontológicos o de formación natural, que existan bajo o sobre la superficie del territorio nacional o en la plataforma submarina de sus aguas jurisdiccionales y cuya conservación interesa a la historia, al arte o la ciencia; los santuarios de la naturaleza; los monumentos, estatuas, columnas, pirámides, fuentes, placas, 
coronas, inscripciones y, en general, los objetos que estén destinados a permanecer en un sitio público, con carácter conmemorativo. Su tuición y protección se ejercerá por medio del Consejo de Monumentos Nacionales, en la forma que determine la presente ley.

Esta tensión se produce entre la propiedad indígena y la propiedad del Estado sobre las tierras en que se emplazan los objetos de culto, restos humanos o espacios ceremoniales y otros de significación cultural y espiritual para los pueblos indígenas que son declarados monumentos nacionales. La segunda tensión se produce a propósito del modelo de gestión o administración de estos espacios territoriales y el patrimonio cultural indígena, ya que se ha confiado la administración de estos espacios a agencias estatales públicas o privadas con mandato público, como son el Consejo de Monumentos Nacionales y la Corporación Nacional Forestal, respectivamente. El Estado ha desestimado las demandas indígenas dirigidas a la demarcación y restitución del territorio donde se emplaza este patrimonio cultural, desplazándolos de sus tierras ancestrales (Yáñez, 2017: 5-8).

Cabe preguntarse, entonces, cómo se protegen los derechos indígenas cuando estos espacios y el patrimonio cultural han sido incorporados sin su consentimiento como parte de parques nacionales y, como consecuencia de ello, se limita el acceso indígena a estas tierras, se restringen sus actividades culturales o se confiscan objetos de culto o incluso restos humanos de sus antepasados (Yáñez, 2017: 5-8).

\section{Ley 20.249 (2008), que crea el Espacio Costero Marino de los Pueblos Originarios (ECMPO)}

Reconoce el patrimonio de los pueblos originarios, ya que su objetivo es resguardar el uso consuetudinario de dichos espacios, a fin de mantener las tradiciones y el uso de los recursos naturales por parte de las comunidades vinculadas al borde costero (Chuvretovic, 2016: 153-164).

\section{Ley 21.045 (2018), crea el Ministerio de las Culturas, las Artes y el Patrimonio}

Para hablar de la creación de este ministerio, es necesario tener presente el proceso de consulta previa a los pueblos indígenas sobre el borrador del proyecto de ley de Ministerio de las Culturas, las Artes y el Patrimonio.

A este proceso de consulta previa, fueron convocados los pueblos aymara, quechua, atacameño o lickanantay, colla, diaguita, rapa nui, mapuche, yagán y kawésqar, además de las comunidades de afrodescendientes en Arica y Parinacota, bajo invitación especial.

El proceso se desarrolló de manera flexible, sustentado en el reconocimiento de las dinámicas de las instituciones y formas de organización de los pueblos consultados 
y en común acuerdo. La convocatoria estuvo dirigida tanto a comunidades y asociaciones indígenas formalizadas como a organizaciones indígenas no formales, artistas y cultores vinculados y vinculadas a la institución, organizaciones gremiales y otras.

A nivel nacional se efectuaron 510 encuentros de consulta, por entonces en las quince regiones del país y en Rapa Nui, más el Encuentro Nacional de Consulta Previa. Participaron a nivel nacional 2.051 organizaciones indígenas y afrodescendientes. La participación de los representantes y miembros de las organizaciones fue sistemática a lo largo del proceso, registrándose 11.188 asistencias en todas las regiones.

En cada región culminó el proceso en un encuentro de cierre regional, o bien de cierre por pueblo participante, definiendo acuerdos y disensos regionales frente a la medida. El encuentro nacional fue una instancia solicitada por los pueblos y comunidades participantes que congregó en total a 212 representantes de todas las regiones y pueblos convocados, designados y designadas en sus territorios. Se celebró en la ciudad de Valparaíso los días 21 y 22 de marzo de 2015, instancia en la que se ratificaron los acuerdos regionales, previo consenso interno por pueblo o por región respecto de las características específicas de estos acuerdos, logrando llegar a acuerdos nacionales. Se establecieron en el encuentro: acuerdos en torno a la medida consultada y compromisos programáticos a desarrollar en el periodo que antecede la creación del Ministerio.

La ley entró en vigor el 1 de marzo de 2018, cumpliendo con los acuerdos de consulta. Se destacan los siguientes artículos relacionados con los derechos culturales:

Artículo 1

Créase el Ministerio de las Culturas, las Artes y el Patrimonio, ${ }^{6}$ y fijase como su ley orgánica la contenida en este texto. Esta ley se regirá por los siguientes principios:

1. De diversidad cultural. Reconocer y promover el respeto a la diversidad cultural, la interculturalidad, la dignidad y el respeto mutuo entre las diversas identidades que cohabitan en el territorio nacional como valores culturales fundamentales.

2. De democracia y participación cultural. Reconocer que las personas y comunidades son creadores de contenidos, prácticas y obras con representación simbólica, con derecho a participar activamente en el desarrollo cultural del país; y tienen acceso social y territorialmente equitativo a los bienes, manifestaciones y servicios culturales.

3. De reconocimiento cultural de los pueblos indígenas. Reconocer, respetar y promover las culturas de los pueblos indígenas, sus prácticas ancestrales, sus creencias, su historia y su cosmovisión, teniendo especial consideración con el desarrollo de la cultura, las artes y el patrimonio cultural indígena. ${ }^{7}$

6. Esta indicación consagra el acuerdo 2 de la Consulta Previa Libre e Informada para la creación del Ministerio: «Que la nueva institucionalidad cultural se denominará "Ministerio de las Culturas, las Artes y el Patrimonio"».

7. Este principio consagra el Acuerdo 3 de la Consulta Previa, Libre e Informada a los pueblos originarios aymara, quechua, atacameño o lickanantay, colla, diaguita, rapa nui, mapuche, yagán y kawésqar, 
4. De respeto a la libertad de creación y valoración social de los creadores y cultores. Reconocer y promover el respeto a la libertad de creación y expresión de creadores y cultores, y a la valoración del rol social de éstos en el desarrollo cultural del país.

\section{Reconocimiento del pueblo chango}

El proceso de reconocimiento legal del pueblo chango comienza en el Congreso $\mathrm{Na}$ cional el año 2017, con el ingreso del proyecto que modifica la Ley 19.253. Esta moción parlamentaria fue impulsada por un constante activismo de las comunidades que se autoidentifican como pertenecientes al pueblo chango.

El 17 de octubre de 2020 entró en vigor la modificación a la Ley 19.253, a través del artículo único de la Ley 21.273. Con la modificación, el artículo 1 de la Ley 19.253 señala:

El Estado reconoce que los indígenas de Chile son los descendientes de las agrupaciones humanas que existen en el territorio nacional desde tiempos precolombinos, que conservan manifestaciones étnicas y culturales propias siendo para ellos la tierra el fundamento principal de su existencia y cultura. El Estado reconoce como principales etnias indígenas de Chile a: la mapuche, aimara, rapa nui o pascuenses, la de las comunidades atacameñas, quechuas, collas, diaguita y chango del norte del país, las comunidades kawashkar o alacalufe y yámana o yagán de los canales australes. El Estado valora su existencia por ser parte esencial de las raíces de la Nación chilena, así como su integridad y desarrollo, de acuerdo a sus costumbres y valores.

Es deber de la sociedad en general y del Estado en particular, a través de sus instituciones, respetar, proteger y promover el desarrollo de los indígenas, sus culturas, familias y comunidades, adoptando las medidas adecuadas para tales fines y proteger las tierras indígenas, velar por su adecuada explotación, por su equilibrio ecológico y propender a su ampliación. ${ }^{8}$

\section{Sistema de propiedad intelectual en Chile, conocimientos y expresiones culturales indígenas}

En nuestro país contamos con un sistema de propiedad intelectual, en el que se destacan las siguientes normas:

con la participación especial de la comunidad afrodescendiente de Arica y Parinacota y la comunidad chango en caleta de Chañaral de Aceituno, para la creación del Ministerio de las Culturas, las Artes y el Patrimonio. Encuentro Nacional con 212 representantes de organizaciones indígenas y tribal, ya señaladas, el 22 de diciembre de 2015.

8. El destacado es nuestro. Los nombres de las comunidades aparecen como está escrito en la ley. 


\section{Constitución Política de la República de Chile}

El capítulo 3, «De los derechos y deberes constitucionales», artículo 19:

La Constitución asegura a todas las personas: [...]

25. La libertad de crear y difundir las artes, así como el derecho del autor sobre sus creaciones intelectuales y artísticas de cualquier especie, por el tiempo que señale la ley y que no será inferior a la vida del titular.

El derecho de autor comprende la propiedad de las obras y otros derechos, como la paternidad, la edición y la integridad de la obra, todo ello en conformidad a la ley.

Se garantiza, también, la propiedad industrial sobre las patentes de invención, marcas comerciales, modelos, procesos tecnológicos u otras creaciones análogas, por el tiempo que establezca la ley.

Será aplicable a la propiedad de las creaciones intelectuales y artísticas y a la propiedad industrial lo prescrito en los incisos segundo, tercero, cuarto y quinto del numeral anterior.

En relación con este último inciso, se hace aplicable a la propiedad intelectual e industrial las garantías del derecho de propiedad establecidas en el artículo 19 numeral 24 de la Constitución. Es decir, cualquier regulación al modo de adquirir propiedad intelectual e industrial, sus limitaciones y obligaciones deben estar establecidas por ley.

\section{Ley 17.336 (1970), Propiedad Intelectual, artículo 1}

Los derechos de autor corresponden a aquellos derechos que, por el solo hecho de la creación de las obras de la inteligencia en los dominios literarios, artísticos y científicos, cualquiera sea su forma de expresión, y los derechos conexos que ella determina.

Los derechos de autor requieren de originalidad y no de registro para que existan. Esto quiere decir que el autor es titular exclusivo del derecho moral de por vida. El derecho moral es transmisible por causa de muerte al cónyuge sobreviviente y a los sucesores $a b$ intestato del autor. Éste es inalienable, es decir, no puede ser transferido por medios de contratos (artículos 15 y 16). En cambio, el derecho patrimonial se puede transferir total o parcialmente y autorizar su utilización por terceros (artículo 17).

El plazo de protección es de toda la vida del autor y se extiende hasta por 70 años más, contados desde la fecha de su fallecimiento (artículo 10).

Pertenecen al Patrimonio Cultural Común, artículo 11:

[...] b) La obra de autor desconocido, incluyéndose las canciones, leyendas, danzas y las expresiones del acervo folklórico; [...]

Las obras del patrimonio cultural común podrán ser utilizadas por cualquiera, siempre que se respete la paternidad y la integridad de la obra. 
Así, los conocimientos tradicionales indígenas serían parte del dominio público, ya que no cuentan con un autor conocido. El dominio público configura un estatuto de protección que garantiza el libre acceso y la no apropiación de aquellos elementos que forman parte de su acervo.

A su vez, existe un plazo de protección, situación que no tiene relación con el traspaso de estos conocimientos de generación en generación, como ocurre al interior de comunidades. La noción del tiempo en este punto es abordada desde una dimensión particular por parte de los pueblos indígenas.

\section{Ley de Propiedad Industrial 19.039}

En nuestra legislación no existen menciones expresas a los conocimientos tradicionales. Sin embargo, podemos mencionar la modificación de febrero de 2005 al artículo 3, inciso tercero de la Ley de Propiedad Industrial, que señala:

La presente ley garantiza que la protección conferida por los derechos de propiedad industrial que aquí se regulan se concederá salvaguardando y respetando tanto el patrimonio biológico y genético como los conocimientos tradicionales nacionales. El otorgamiento de los derechos de propiedad industrial que constituyan elementos protegibles, que hayan sido desarrollados a partir del material obtenido de dicho patrimonio o de dichos conocimientos, estará supeditado a que ese material haya sido adquirido de conformidad con el ordenamiento jurídico vigente.

Esta modificación se traduce en la suposición de que la obtención del material haya sido legal, o que puede conducir a la existencia de regímenes institucionales de acceso tanto a recursos biológicos y genéticos, como a los conocimientos tradicionales a éstos asociados. Tal cuestión en la actualidad, ante la inexistencia de regulación, queda entregada a la celebración de contratos o convenios de acceso por parte de organismos públicos y universidades, que se han elaborado desde la perspectiva de cada organismo involucrado, procurando en alguna medida ajustarse a lo dispuesto en el Convenio sobre la Diversidad Biológica. Esta modificación presenta una mirada hacia el futuro, en la cual la adquisición del material biológico y genético y de los conocimientos tradicionales asociados deberán ceñirse al régimen de acceso que se establezca a nivel normativo, cuestión que deberá considerarse por el Instituto de Propiedad Industrial (Inapi) al momento de otorgar derechos de propiedad industrial. Por ahora, ese régimen no existe y esta disposición carece de operatividad práctica (Ramírez, 2015: 178-179).

Otro aspecto que considerar en la ley de propiedad industrial son las marcas, es decir, cualquier signo que sea susceptible de representación gráfica, capaz de distinguir en el mercado productos, servicios o establecimientos industriales o comercia- 
les. El elemento aquí fundamental es la «distinción», es decir, que no pueden tener un carácter genérico, indicativo o descriptivo.

La marca otorga a su titular un derecho exclusivo y excluyente de utilizarla en el tráfico económico, mientras que el plazo de protección es temporal y territorial, es decir, sólo a nivel nacional y por diez años renovables indefinidamente por periodos iguales, previo pago de la tasa correspondiente.

En la experiencia de trabajo territorial, hemos escuchado numerosas aprehensiones respecto de las marcas otorgadas. Se ha indicado que muchas de ellas son apropiaciones culturales, por ejemplo, respecto de denominaciones en lenguas indígenas, cuestión que debe ser analizada desde varias perspectivas, ya que no se debe olvidar que las lenguas indígenas se encuentran en un proceso de revitalización. Por lo mismo, cabe preguntarse si su uso, más que una apropiación cultural, constituiría un acto de difusión o un uso común de una lengua como cualquier otra. En este sentido, el debate se encuentra abierto para determinar si es necesario o no señalar un límite al uso de denominaciones en lenguas indígenas, sin perjuicio de que existe un sinfín de otro tipo de apropiaciones culturales.

Un ejemplo que nos puede ilustrar es la resolución del Inapi del 15 de noviembre de 2016, que rechazó una solicitud marcaria, fundado en las causales de irregistrabilidad contenidas en las letras e) y f) del artículo 20 de la Ley de Propiedad Industrial, indicando que:

Puesto que la marca solicitada contenía una expresión correspondiente a una etnonimia, específicamente, mapuche, con la que se identifica un pueblo originario que habita principalmente en el sur de Chile, de modo particular en la región histórica de Arauco (los llamados araucanos), o de la actual región de la Araucanía y sus descendientes. Por lo anterior, carecía de distintividad y era inductiva a error, resultando irregistrable, toda vez que los derechos de propiedad industrial se conceden salvaguardando y respetando tanto el patrimonio biológico y genético como también los conocimientos tradicionales nacionales, entre los cuales se encontraban los de los pueblos originarios, especialmente, en este caso en particular, toda vez que es habitual encontrar en el comercio productos medicinales de origen herbario, cuyos componentes u fabricación tienen su origen en la cultura señalada.

Revisada en alzada, el Tribunal de Propiedad Industrial (TDPI), mediante sentencia dictada el 21 de febrero 2017 (rol 2552-16), confirmó lo resuelto por el Inapi. Producto de aquello es que la presente quedaba incursa en las causales invocadas, atendido que resultaba indicativa de procedencia, en caso de tratarse de hierbas de origen mapuche, o bien inductiva en error o engaño, en caso de no corresponder efectivamente, a dicho origen particular.

En el contexto internacional, la propiedad intelectual ha sido objeto de análisis para su utilización como mecanismo de protección de los conocimientos tradiciona- 
les indígenas. Los conocimientos tradicionales son un conjunto de elementos difíciles de identificar, ya que están en constante evolución, lo que impide tener una visión estática o rígida de los mismos. La Organización Mundial de la Propiedad Intelectual (OMPI) ha optado por definirlos de una forma abierta. Esto es, sin otorgar una definición exacta del término, esta organización identifica los principales elementos que lo constituyen dentro del área artística, literaria y científica. Estos elementos son invenciones, descubrimientos científicos, diseños, marcas, símbolos, información sin revelar y prestaciones al público. Todos estos trabajos deben ser el resultado de una actividad intelectual.

A su vez, se requiere que estas actividades sean desarrolladas de forma tradicional, lo que implica la transmisión de estos conocimientos de generación en generación, por lo general vinculadas con un grupo particular de personas a cierto territorio. El traspaso generacional del conocimiento tradicional fundamenta el carácter no sistemático o poco metódico de su creación, ya que el proceso de creación no suele estar formalmente documentado y su traspaso muchas veces es informal. (Walker, 2020: 57-61).

Para los pueblos indígenas, el uso de este sistema de propiedad intelectual para la protección de sus conocimientos tradicionales no está exento de aprehensiones, ya que han experimentado usurpación de estos conocimientos a través del uso de este mismo sistema.

La Organización Mundial de la Propiedad Intelectual (OMPI) ha promovido el uso de este sistema de propiedad intelectual para la protección de estos conocimientos tradicionales, existiendo numerosos ejemplos comparados en este sentido, en que pueblos indígenas han optado por su uso. Un ejemplo encaminado a esto es el caso del Sámikopiiika, la organización de derechos de reproducción sami. Se trata de una organización de derechos de reproducción que representa a los titulares de derechos del pueblo originario sami en Noruega, Suecia, Finlandia y la Federación de Rusia. Según su sitio web, Sámikopiiika ha empezado a trabajar en los aspectos de los conocimientos tradicionales de los pueblos indígenas relacionados con el derecho de autor, labor que se ha convertido en un proyecto independiente para sus actividades (Torse y Anderson, 2012: 88).

A pesar de este uso descrito, la protección de los conocimientos tradicionales indígenas no está exenta de críticas, ya que las características de este sistema de propiedad intelectual no coinciden muchas veces con la protección demandada por el mundo indígena. Por ejemplo, en el caso del derecho de autor, los conocimientos tradicionales tienen una base colectiva, que no tiene que ver con el número de autores (obra colectiva), sino más bien con que no se conoce al autor del conocimiento, porque éste ha pasado de generación en generación, adaptándose a la realidad contemporánea para su subsistencia. Entonces, algunos autores hablan más bien de «guardianes» que custodian su contenido y uso. 
Tampoco existe consenso respecto de la explotación económica de este conocimiento tradicional, el que corre el riesgo permanente de transformarse en un bien de mercado destinado al consumo masivo como objetos étnicos, situación que conlleva el peligro latente de desvirtuar las claves culturales profundas de las identidades indígenas. Éstas y otras críticas han llevado a sostener a varios autores que la protección de estos conocimientos tradicionales debiese provenir de un sistema sui generis de protección, ya que se trataría de un tipo distinto de propiedad intelectual.

Sin perjuicio de lo señalado, ya hemos analizado en este artículo los instrumentos internacionales que reconocen este derecho de propiedad intelectual de los pueblos indígenas respecto de sus sistemas culturales (DNUDI y DADPI).

Este tema es emergente en el derecho internacional de los derechos humanos indígenas, y requerirá de un esfuerzo intergubernamental con la participación vinculante de los pueblos indígenas para lograr la protección anhelada. Los conocimientos tradicionales de los sistemas culturas indígenas son susceptibles de constitución de derechos de propiedad intelectual. Sin embargo, esto podría limitar su regeneración y revitalización, ya que los inmoviliza en un momento determinado, además de las dificultades respecto de los plazos de protección y dominio público, entre otros.

Por último, en este punto es dable señalar que hoy los miembros de la OMPI están elaborando un instrumento internacional -o más de uno- que pueda dar protección eficaz a los conocimientos y las expresiones culturales tradicionales y regular la interrelación de la propiedad intelectual con el acceso a los recursos genéticos y la participación en los beneficios. En un instrumento jurídico internacional se definiría qué se entiende por conocimiento tradicional y expresión cultural tradicional, quiénes serían los titulares de los derechos, cómo se resolverían concurrentes de distintas comunidades y qué derechos y excepciones deberían aplicarse.

Afinar los detalles es una tarea compleja y existen opiniones divergentes acerca del mejor camino a seguir, por ejemplo, acerca de si corresponde valerse de derechos asimilables a los de propiedad intelectual para proteger las formas tradicionales de innovación y creatividad. ${ }^{9}$

Del análisis de la principal normativa nacional en materia de derechos culturales indígenas, podemos concluir que existe una normativa atomizada, que regula aspectos específicos de los elementos que constituyen los patrimonios culturales indígenas; por ejemplo, la legislación en materia de espacio costero marino de pueblos originarios. Sin embargo, nuestra legislación tiene brechas de implementación respecto de la normativa internacional ratificada. A su vez, no cuenta con una normativa específica sobre la materia y existe la necesidad por parte de los pueblos indígenas de

9. «Propiedad Intelectual y recursos genéticos, conocimientos tradicionales y expresiones culturales tradicionales», Organización Mundial de la Propiedad Intelectual, 2015, p. 49, disponible en https://bit. ly/344pMer. 
protección, reconocimiento y revitalización de sus patrimonios según sus normativas propias y autónomas.

\section{Posibles alternativas para la protección de los patrimonios culturales indígenas}

Nos corresponde ahora explorar, de acuerdo con el escenario expuesto, alternativas que nos posibiliten proponer algún aporte al escenario de la protección de los sistemas culturales indígenas en el Chile actual.

Una mirada respecto de la implementación de los derechos en el contexto regional nos permite constatar el evidente atraso que tiene Chile en materia de reconocimiento de derechos de los pueblos indígenas. Esto queda expresamente de manifiesto al comprobar que nuestro país es de los últimos — junto con Surinam y Uruguayen que no se ha reconocido de forma explícita a los pueblos indígenas en su carta fundamental.

En este contexto, parece complejo encontrar alternativas estructurales que tiendan a la protección real de los patrimonios culturales indígenas, esto a nivel de legislación interna, la cual hemos visto es dispersa y hasta contradictoria. Pese a ello, podemos identificar ciertas acciones puntuales que pueden contribuir a este escenario, considerando que aún se está a la espera del tantas veces prometido y postergado reconocimiento constitucional a los pueblos indígenas para, a través de esa puerta, aspirar a la construcción de un Estado plurinacional. Situación que, desde la perspectiva de las reivindicaciones indígenas, pueda considerar el reconocimiento del pluralismo jurídico, que podría permitir aspirar a una sociedad más justa.

\section{Reconocimiento de los pueblos indígenas en la próxima constitución}

Teniendo presente que un primer paso en materia de protección de los derechos culturales indígenas es el reconocimiento constitucional, existen otros caminos complementarios de protección que pueden permitir el ejercicio de los derechos colectivos e individuales que pueda reconocer nuestra futura carta de navegación.

\section{El reconocimiento de los derechos colectivos de los pueblos indígenas}

El reconocimiento de los derechos colectivos de los pueblos indígenas es una de las alternativas de protección, ya que es una tendencia internacional que prima tanto entre especialistas como en los discursos públicos del movimiento indígena internacional, lo cual implica entender al derecho de propiedad colectiva sobre el patrimonio cultural propio y la propiedad intelectual desde una perspectiva sui generis. Esto significa que el contenido sustantivo de este derecho de propiedad sea otorgado por los propios sistemas culturales indígenas. Al respecto, la mayor parte de los actores indígenas y 
autores están de acuerdo en que esta propiedad debería ser de carácter colectivo, inalienable, perpetuo, indivisible, inembargable e imprescriptible, resguardando en todo momento los derechos soberanos de los pueblos indígenas sobre sus recursos.

\section{Promoción de la educación formal y no formal}

La promoción de la educación formal y no formal es otra alternativa de protección que complementa el reconocimiento constitucional y de los derechos colectivos de los pueblos indígenas. Incentivar el conocimiento de los pueblos indígenas desde un verdadero enfoque de derechos humanos e intercultural puede permitir a todos los integrantes de nuestras sociedades conocer su historia, conocimientos y expresiones culturales tradicionales. Además, promoverá una educación que cuente la historia de lo que sufrieron los pueblos indígenas desde la formación de este Estado nación y desde el primer hecho colonial en nuestro continente.

La promoción de la educación en materia de derechos culturales indígenas posibilita llevar a cabo una labor preventiva respecto de las vulneraciones, ya analizadas, que sufren a diario los pueblos indígenas, ya que incluso si existiera una normativa propia de los pueblos indígenas, ésta se puede vulnerar, como sucede hoy con diversas normativas vigentes.

\section{Creación, seguimiento y evaluación de políticas públicas,} planes y programas con enfoque de derechos humanos

Otra posibilidad es la creación, seguimiento y evaluación de políticas públicas, planes y programas con enfoque de derechos humanos, en los que el eje articulador del ejercicio integral de derechos humanos sea el derecho colectivo de participación, establecido en el artículo 7 del Convenio 169 de la OIT.

Un ejemplo de esta alternativa de protección a nivel de un programa y planes dirigidos a los pueblos indígenas es el programa social «Fomento y difusión de las artes y las culturas de los pueblos indígenas», ejecutado por la Subdirección de Pueblos Originarios del Servicio Nacional del Patrimonio Cultural, que tiene su origen en el proceso de consulta previa a los pueblos indígenas.

En esta consulta previa, los propios pueblos indígenas autodiagnosticaron una crisis de reproducción de los sistemas culturales tradicionales indígenas y afrodescendiente, lo que tiene como efecto la baja valoración y decaimiento de las expresiones culturales y artísticas tradicionales, junto con las contemporáneas, que proporcionan la base cultural de cualquier agrupación humana que comparte una identidad colectiva anclada en una cultura común.

En este programa se pone en ejercicio el derecho colectivo de participación a través de la ejecución de diálogos de priorización, seguimiento y evaluación con orga- 
nizaciones indígenas y afrochilenas, proceso que se plasma en la creación de planes de revitalización cultural indígena y afrodescendiente —estos últimos en Arica y Parinacota - suscritos entre la Subdirección Nacional de Pueblos Originarios y las organizaciones indígenas en las dieciséis regiones del país, además del territorio insular de Rapa Nui. Tales planes tienen una vigencia de carácter bienal, es decir, su ejecución está articulada en ciclos de dos años y constituyen la carta de navegación de trabajo común con las organizaciones indígenas y afrodescendientes en cada región, priorizando iniciativas de revitalización, celebrando convenios de colaboración con las propias organizaciones indígenas en la mayoría de los casos. ${ }^{10}$

En la actualidad, el ejercicio del derecho colectivo de participación es una necesidad transversal, no solo en las sociedades indígenas, a partir del contexto experimentado en Chile desde el 18 de octubre de 2019 a la fecha.

\section{Ejercicio del derecho propio de los pueblos indígenas}

El ejercicio del derecho propio de los pueblos indígenas, a través de la creación de registros y protocolos autónomos respecto del uso, manejo, acceso y otros aspectos que quieran regular los pueblos indígenas en relación con sus patrimonios culturales y su interacción con agentes externos, ya sean públicos o privados. Estos protocolos, que son en la práctica una forma de regulación de las relaciones interétnicas a nivel local, cobran especial relevancia en temas como el etnoturismo, la investigación académica y, en general, cualquier aspecto relacionado con la difusión de los conocimientos tradicionales de esas comunidades, expresiones culturales tradicionales y recursos genéticos.

El desarrollo de este tipo de protocolos autónomos puede tener varios efectos colaterales. En primer lugar, son un ejercicio concreto de autodeterminación, que fortalece internamente a las comunidades y pueblos, pues les posibilita generar conocimientos colectivos. Además de consensuar una forma de relacionamiento con terceros, puede también tener un efecto tangencial de co-construcción de sistemas normativos indígenas en donde el derecho consuetudinario pasa a tener un rol protagónico.

Una consecuencia indirecta del eventual uso y aplicación de estos protocolos es que contribuyen al fortalecimiento de las relaciones interculturales. En este escenario, los propios colectivos indígenas y las personas ajenas a ellos salen fortalecidos a partir del protagonismo que adquieren en esa relación las comunidades dueñas de esos conocimientos.

10. «Síntesis nacional del Programa de fomento y difusión de las artes y las culturas de los pueblos indígenas», Ministerio de las Culturas, las Artes y el Patrimonio, 2 de mayo de 2018, disponible en https:// bit.ly/3a6iBWX. 
Un ejemplo es el Protocolo de Buenas Prácticas para la Protección del Patrimonio Cultural Indígena Yagán del año 2017, elaborado por la comunidad indígena yagán en bahía Mejillones, Puerto Williams, región de Magallanes y la Antártica Chilena, que contó con la colaboración de la Subdirección de Pueblos Originarios del Servicio Nacional del Patrimonio Cultural, del Ministerio de las Culturas, las Artes y el Patrimonio. Destaca el punto 1 de los 15 que componen este protocolo:

Declaramos que cualquier persona o entidad pública o privada que tenga la intención de trabajar en materias vinculadas a nuestro patrimonio cultural indígena yagán o que puedan afectarlo de alguna forma, debe considerar las siguientes directrices:

Sobre la existencia del pueblo yagán:

1. Como pueblo yagán, somos un pueblo milenario, con 7.000 años de presencia aproximadamente en nuestro territorio, desde mucho antes de la creación de los actuales Estados chileno y argentino con sus fronteras. No obstante la usurpación de nuestro territorio, el desplazamiento obligatorio, secuestros, la imposición de creencias religiosas y la prohibición de prácticas culturales como la lengua, la realización de ceremonias como el chiajaus y la kina, la navegación, con sus actuales límites y vedas, y la caza de nuestros alimentos tradicionales, como aves y lobos marinos, hasta el día de hoy nuestro pueblo se encuentra vivo, manteniendo nuestra consciencia de identidad indígena colectiva.

De acuerdo con esto, demandamos que no se haga referencia de «ultimo» para referirse a alguno de los integrantes de nuestra comunidad. ${ }^{11}$

Otro ejercicio del derecho propio de los pueblos indígenas es la creación de registros autónomos respecto de sus conocimientos y expresiones culturales tradicionales o contemporáneas. Quizá, en una primera etapa, por temas de financiamiento, será necesaria la colaboración de los órganos públicos relacionados con la especialidad de la materia cultural. Estos procesos se deberán llevar a cabo siempre con enfoque de derechos humanos, facilitando la participación indígena. Un ejemplo comparado en esta materia es el caso del pueblo kuna en Panamá, que cuenta con este tipo de registros autónomos, caso ya analizado.

Las alternativas de protección planteadas de reconocimiento constitucional; de derechos colectivos; la promoción de la educación formal y no formal; la creación, seguimiento y evaluación de políticas públicas, planes y programas con enfoque de derechos humanos; y el ejercicio del derecho propio de los pueblos indígenas, se complementan a su vez con los mecanismos de protección propios de cada uno de los tratados internacionales analizados.

11. Comunidad Indígena Yaghan de Bahía Mejillones «Protocolo de buenas prácticas para la protección del patrimonio cultural indígena yagán», 2017. Será posible descargar durante el próximo año 2021 en https://bit.ly/37KUs6R. 
Por último, dentro de estas alternativas no se puede dejar de mencionar el rol del activismo que siguen a diario las organizaciones indígenas en la defensa de sus derechos. Este activismo tiene múltiples dimensiones, que muestran la relevancia del rol del activismo judicial nacional e internacional, el activismo legislativo, medioambiental y tantos otros.

\section{Conclusiones}

A contar de lo descrito en este trabajo, se pueden extraer algunas conclusiones preliminares. Resulta evidente que, para avanzar en el reconocimiento, ejercicio y protección de los derechos culturales indígenas, se requiere la creación de políticas públicas que pongan en ejercicio el enfoque de derechos humanos. Dentro de este enfoque, la participación directa de los pueblos indígenas, establecida en diversos instrumentos internacionales - entre ellos, el Convenio 169 de la OIT_-, resulta crucial. El enfoque de derechos humanos implica un cambio de paradigma en la relación del Estado con los pueblos indígenas dentro de la historia de las políticas públicas puestas en ejercicio en Chile. El enfoque de derechos humanos supone, además, una apuesta y a la vez un compromiso que cruza toda la relación entre el Estado y los pueblos indígenas. No es lo mismo que los órganos de la administración del Estado pregunten a una comunidad indígena si la carretera pasa por encima del cementerio indígena o unos metros más allá, que el abrir un diálogo respecto de qué necesitan en realidad en un determinado territorio. He ahí la fortaleza de la participación en todo el proceso de diálogo intercultural.

La puesta en práctica del enfoque de derechos humanos permite ejercer los derechos humanos de forma integral, es decir, respetando su carácter indivisible, interdependiente y universal, considerando que el carácter universal debe respetar la diversidad cultural, y que no se debe imponer una cultura hegemónica por sobre otra subordinada. A su vez, el mundo indígena no podría relativizar la aplicación integral de los derechos humanos, a excusa de una práctica cultural.

Volviendo a la participación indígena en políticas públicas, esto no implica renunciar a las posibilidades del diálogo proactivo. De eso se trata precisamente el ejercicio de la participación: del diálogo que busca en todo momento el bien común. Estamos demasiado acostumbrados en la historia de las políticas públicas en Chile no sólo a que no haya participación indígena en legislaciones que les afectan directamente, sino que, peor aún, que cualquier posible inclusión originaria sea negada o minimizada bajo la excusa de un posible conflicto. El movimiento indígena tanto a nivel global como regional y local ha dado suficientes pruebas históricas de que siempre y bajo las más diversas circunstancias ha estado dispuesto a dialogar con el Estado.

Es esta enseñanza histórica la que no podemos dejar de mencionar hoy, en momentos en que se encuentra en trámite legislativo el proyecto que viene a modificar 
la actual Ley de Monumentos Nacionales. Es indiscutible que esta ley del año 1970 requiere de una urgente modificación. Esto es una necesidad para los distintos sectores implicados en la dinámica de los patrimonios culturales, entre ellos los pueblos indígenas como uno de los principales. La participación de los pueblos indígenas y afrodescendientes - reconocido como pueblo tribal afrodescendiente chileno por la Ley 21.151 de 2019- mediante un proceso de consulta previa, que es parte de la legislación interna vigente hoy dentro de Chile (Convenio 169 de la OIT), es un deber y una obligación contraída por el Estado chileno, que debe respetar.

Existen varios caminos por recorrer para alcanzar un verdadero respeto por los derechos culturales indígenas; reconocer a este otro u otra como sujeto de derechos colectivos e individuales, que tienen derecho a su libre determinación, a vivir sus propias culturas según sus propios modelos de desarrollo, sistemas jurídicos, instituciones propias y representación política. El ejercicio pleno de estos derechos nos permitirá crear puentes solidos de interculturalidad que posibiliten descolonizarnos y reconocer nuestras propias identidades individuales y colectivas dentro de estos territorios llamados Chile.

\section{Agradecimientos}

Agradezco infinitamente el cariño, la confianza y la oportunidad que me han entregado cada una de las personas que he conocido en este proceso de aprendizaje, que me están permitiendo reconocer y sentir el mundo desde otras miradas desconocidas.

\section{Referencias}

Chuvretovic, Teresita (2016). «Institucionalidad e instrumentos jurídicos para la protección del patrimonio cultural». Revista de Derecho Administrativo Económico, 23: 153-164. DOI: 10.7764/redae.23.9.

De Sousa Santos, Boaventura (2016). Descolonizando el saber, reinventar el poder. Santiago: Lom.

EtXeberria, Xavier (2006). «La tradición de los derechos humanos y los pueblos indígenas: Una interpelación mutua». En Mikel Berraondo López (coordinador), Pueblos indígenas y derechos humanos (pp. 63-83). Barcelona: Instituto de Derechos Humanos, Universidad de Deusto.

Huenchuan, Sandra (2004). «Propiedad Cultura e Intelectual de los Pueblos Indígenas: Objetos y Enfoques de Protección». Revista Austral de Ciencias Sociales, 8: 81-96. 2004.

RAMíREZ, Daniella (2015). «La conservación de los conocimientos tradicionales indígenas: Una tarea pendiente y necesaria». Revista de Derecho Ambiental, 2: 167-194. Disponible en https://bit.ly/3me1KDV. 
Torse, Molly y Jane Anderson (2012). La propiedad intelectual, la salvaguardia de las culturas tradicionales. Ginebra: OMPI.

VARGAS, Edmundo (2017). Derecho internacional público. Santiago: El Jurista.

Walker, Elisa (2020). Manual de propiedad intelectual. Santiago: Thomson Reuters.

YáñEZ, Nancy (2017). «Marco jurídico para el análisis del patrimonio cultural y los derechos de los pueblos indígenas en Chile: Identidades en tensión, un análisis de caso atacameño o lickanantay». Conferencia presentada en Coloquios Regionales de Antofagasta, «El patrimonio ¿bien común o bien de mercado?». Antofagasta.

YRIGOYEN, Raquel (2011). «El derecho a la libre determinación del desarrollo, la participación, la consulta y el consentimiento». En Marco Aparicio (editor). Los derechos de los pueblos indígenas a los recursos naturales y al territorio: Conflictos $y$ desafíos en américa Latina. Barcelona: Icaria.

\section{Sobre la autora}

Daniela Andrea Abarzúa Órdenes es abogada. Diplomada en Propiedad Intelectual, Pontificia Universidad Católica de Chile. Diplomada en Estudio Internacional en Litigio Estratégico en Derechos Indígenas, Pontificia Universidad Católica del Perú e Instituto Internacional de Derecho y Sociedad. Actualmente cursando el diploma internacional en Sistemas Jurídicos Indígenas, Pluralismo Jurídico Igualitario y Descolonización, Instituto Internacional de Derecho y Sociedad del Perú, Instituto Interamericano de Derechos Humanos y Universidad de Brasilia. Coordinadora Nacional de la Subdirección Nacional de Pueblos Originarios del Servicio Nacional del Patrimonio Cultural, Ministerio de las Culturas, las Artes y el Patrimonio de Chile. Su correo electrónico es dabarzuaordenes@gmail.com. (D) https://orcid. org/0000-0002-6898-8268. 
El Anuario de Derechos Humanos es una publicación semestral de referencia y consulta en materia de derechos humanos y campos afines. Busca ser un espacio de discusión de los temas centrales en el ámbito nacional e internacional sobre derechos humanos. Es publicado desde 2005 por el Centro de Derechos Humanos de la Facultad de Derecho de la Universidad de Chile.

\author{
EDITORA \\ Claudia Iriarte Rivas \\ ciriarter@derecho.uchile.cl \\ SITIO WEB \\ anuariocdh.uchile.cl \\ CORREO ELECTRÓNICO \\ anuario-cdh@derecho.uchile.cl \\ LICENCIA DE ESTE ARTÍCULO \\ Creative Commons Atribución Compartir Igual 4.o Internacional
}

\author{
\% \\ La edición de textos, el diseño editorial \\ y la conversión a formatos electrónicos de este artículo \\ estuvieron a cargo de Tipográfica \\ (www.tipografica.io)
}

